\title{
INEZIL PENNA MARINHO: LUGARES E PRÁTICAS EM PERIÓDICOS DA EDUCAÇÃO FÍSICA
}

\author{
INEZIL PENNA MARINHO: PLACES AND PRACTICES IN PHYSICAL \\ EDUCATION JOURNALS
}

INEZIL PENNA MARINHO: LUGARES Y PRÁCTICAS EN PERIÓDICOS DE LA EDUCACIÓN FÍSICA

\author{
Antonio Sergio Francisco Oliveira*, Wagner dos Santos*, Omar Schneider*, \\ Amarílio Ferreira Neto*
}

\section{Palavras-chave \\ História. \\ Educação Física. \\ Memória. \\ Publicações \\ científicas e \\ técnicas.}

Keywords:

History.

Physical Education.

Memory.

Scientific

and technical

publications.

\section{Palabras clave}

Historia de la

Educación Física.

Memoria.

Publicaciones

científicas y

técnicas.
Resumo: 0 trabalho analisa o modo como os lugares ocupados estrategicamente por Inezil Penna Marinho no cenário político e acadêmico influenciaram as trajetórias de sua produção e de suas práticas de circulação intelectual em periódicos nos anos de 19401958. Fundamenta-se na perspectiva da História Cultural e tem como fonte a Revista de Educação Física, Educação Physica, Revista Brasileira de Educação Física e Arquivos da Escola Nacional de Educação Física e Desportos. Marinho, de forma intencional, produziu uma série de registros que demarcaram suas ações e produções, com 0 propósito de preservar sua memória como monumento (LE GOFF, 2003) da Educação Física e dos Esportes no Brasil. A textualidade dos 178 trabalhos mapeados evidenciam o interesse do autor pelas temáticas Educação Física (79), História da Educação Física (69), Teorias Educacionais (11) e Outros (19).

Abstract: The paper examines how places strategically occupied by Inezil Penna Marinho in the political and academic scenario influence the trajectories of his production and practices of intellectual circulation in journals in 1940-1958. It is based on the perspective of Cultural History and its sources include Revista de Educação Física, Educação Physica, Revista Brasileira de Educação Física and Arquivos da Escola Nacional de Educação Física e Desportos. Marinho intentionally produces a series of records that demarcate his actions and productions, with the purpose of preserving his memory as a monument (LE GOFF, 2003) of Physical Education and Sports in Brazil. The 178 studies mapped show the author's interest in topics of Physical Education (79), History of Physical Education (69), Educational Theory (11), and Others (19).

Resumen: El trabajo analiza cómo los lugares ocupados estratégicamente por Inezil Penna Marinho en el escenario político y académico influencian las trayectorias de su producción y de sus prácticas de circulación intelectual en periódicos, en los años de 1940-1958. Se fundamenta en la perspectiva de la Historia Cultural y tiene como fuente: Revista de Educação Física, Educação Physica, Revista Brasileira de Educação Física y Archivos de la Escola Nacional de Educação Física e Desportos. Marinho, de forma intencional, produce una serie de registros que demarcan sus acciones y producciones, con el propósito de preservar su memoria como monumento (LE GOFF, 2003) de la Educación Física y de los Deportes en Brasil. El contexto de los 178 trabajos mapeados evidencia el interés del autor por las temáticas Educación Física (79), Historia de la Educación Física (69), Teorías Educacionales (11) y Otros (19).
Universidade Federal do Espírito Santo. Vitória, ES, Brasil. E-mail: drasfo@ig.com.br

Recebido em: 20-06-2014 Aprovado em: 01-10-2014 (c) (1) (8) Licence 


\section{INTRODUÇÃOO}

A quantidade, a diversidade e a complexidade do conjunto das temáticas enfrentadas por Inezil Penna Marinho continuam a instigar novas pesquisas (NASCIMENTO, 1997; MELO, 1998; FERREIRA NETO, 1999; GOELLNER, 2005; 2009). Neste caso, o estudo em foco se dedica a compreender o modo como os lugares ocupados estrategicamente por esse intelectual, no cenário político e acadêmico, influenciaram os caminhos da sua produção e suas práticas de circulação em periódicos nos anos de 1940 a 1958.

As representações postas em circulação por Marinho não são neutras, tampouco desinteressadas, mas se configuram como práticas intencionais que têm como propósito preservar sua memória como monumento (LE GOFF, 2003) da Educação e dos Esportes no Brasil. Entendemos, como afirma Chartier (1988, p. 17), que

[...] as percepções do social não são de forma alguma discursos neutros, produzem estratégias e práticas [...] que tendem a impor uma autoridade à custa de outros, por elas menosprezados, a legitimar um projeto reformador ou justificar, para os próprios indivíduos, as suas escolhas e condutas.

Fundamentados nos conceitos de lugar (CERTEAU, 2004), memória (LE GOFF, 1998) e de representação (CHARTIER, 1988), procuramos, na construção deste texto, estabelecer a relação entre formação, contexto de atuação e produção acadêmica de Marinho em periódicos.

Os periódicos foram selecionados no Catálogo de periódicos de educação física (19302000), de Ferreira Neto et al. (2002). Para a caracterização da pesquisa, foram escolhidos quatro impressos especializados - Revista de Educação Física, Educação Physica, Revista Brasileira de Educação Física e Arquivos da Escola Nacional de Educação Física e Desportos -, que atenderam ao nosso objetivo, considerando a nossa periodização.

\section{INEZIL PENNA MARINHO: DE LUGARES E ESPAÇOS PRATICADOS EM IMPRESSOS DA EDUCAÇÃO FÍSICA}

Marinho se autodenomina autor de importância na história da Educação Física brasileira, quando registra, em suas obras (MARINHO, 1943, 1952b, 1953, 1954), a memória de suas ações e produções, configurada em monumento (LE GOFF, 2003). Nesse jogo de constituir a própria memória, o autor, de forma intencional, produz uma série de registros que marcam a sua participação em eventos, cursos, palestras, condecorações, títulos e produções científicas.

A seguir, o exemplo no livro História da educação física e dos desportos no Brasil, publicado em 1954 (p. 229-231), em que Marinho destaca sua participação em concursos:

O professor Inezil Penna Marinho vence: Concurso de sentenças sobre Educação Física. 0 item 2 do edital refere-se: as sentenças destinam-se a divulgar os benefícios da Educação Física e deverão por muito o alto valor dos exercícios físicos na preparação do homem integral, sadio de corpo e de espírito. Vence o $1^{\circ}$ lugar com 'A Educação Física fará de cada criança um cidadão útil à pátria'; o $2^{\circ}$ lugar com 'É para o bem de todos que queremos a Educação Física de cada um'; o 3ํlugar com 'Da Educação Física de vossos filhos depende não só a sua constituição física, como também a sua formação moral e ainda o seu desenvolvimento intelectual'; 0 $4^{0}$ lugar com 'A Educação Física torna os indivíduos úteis a si mesmos e aos seus semelhantes'; o 6ㅇ lugar com 'Uma criança sem Educação Física será um cidadão perdido para a Pátria'; $7^{\circ}$ lugar 'As grandes idéias nascem dos grandes cérebros, 
mas, para que se tornem grandes ações, precisam de braços fortes'; $8^{\circ}$ lugar com 'Sobre a fortaleza de seu povo assentam as bases de uma grande nação; a Educação Física fará do Brasil uma grande nação'. Concurso de cartazes para a propaganda da Educação Física. A justificativa do concurso é esta: os cartazes destinam-se a formar um ambiente favorável aos exercícios físicos e deverão evidenciar os efeitos benéficos que os mesmos exercícios proporcionam, de modo que os jovens sejam estimulados à sua prática metódica e constante. 0 professor Inezil Penna Marinho ganhou 0 7º lugar com 'Contribuição ao Histórico da Educação Física no Brasil' e o 9 lugar com Especialização - Fator preponderante na Técnica da Educação Física. Em 19 de outubro de 1942, Inezil Penna Marinho é premiado com a monografia 'A oportunidade da criação da carreira de Técnico de Educação Física', evento que marca seu envolvimento em defesa do profissional de Educação Física.

Ao rastrear os modos de criação dos lugares e dos espaços (CERTEAU, 2004) ocupados por Marinho, é preciso destacar que, de acordo com os estudos e análises dos trabalhos desenvolvidos, muitos desses publicados na Revista Brasileira de Educação Física, há indícios dos usos estratégicos (CERTEAU, 2004) que ele fez de seu cargo público. No exercício da função de Técnico em Educação do Ministério da Educação e Saúde, o autor utilizou-se da autoridade que o cargo Ihe conferia para publicar e afirmar sua representatividade no campo, como exposto na Figura 1.

Figura 1 - Artigo publicado na Revista Brasileira de Educação Física

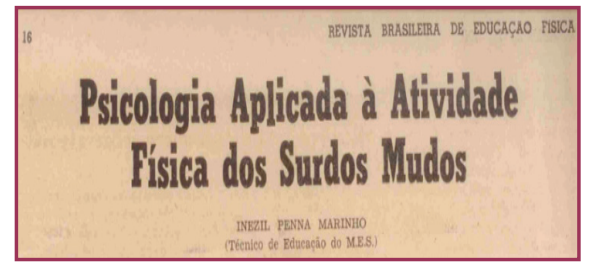

Fonte: Revista Brasileira de Educação Física, v. 3, n. 32, 1946, p. 16.

O uso dessa estratégia mostra que a relação de seu cargo público com a Educação Física forja as formas pelas quais seus artigos chegam ao público leitor. Marinho trabalha com essa perspectiva para demarcar seu lugar, pois, segundo anuncia Certeau (2006, p. 67), "[...] é em função deste lugar que se instauram os métodos, que se delineia uma topografia de interesses, que os documentos e as questões, que lhes serão propostas, se organizam".

A partir de 1946, como podemos observar nas Figuras 2 e 3, Marinho assume a direção da Revista Brasileira de Educação Física, antes dirigida pelo seu fundador, major João Barbosa Leite, que, por motivos financeiros, políticos e administrativos, optou por seu afastamento.

Figura 2 - Capa da Revista Brasileira de Educação Física

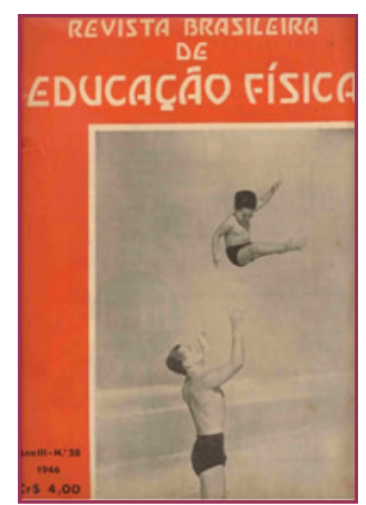

Fonte: Revista Brasileira de Educação Física, v.3, n. 28, p. 1-2, 1946
Figura 3 -Revista Brasileira de Educação Física sob a direção do professor Inezil Penna Marinho

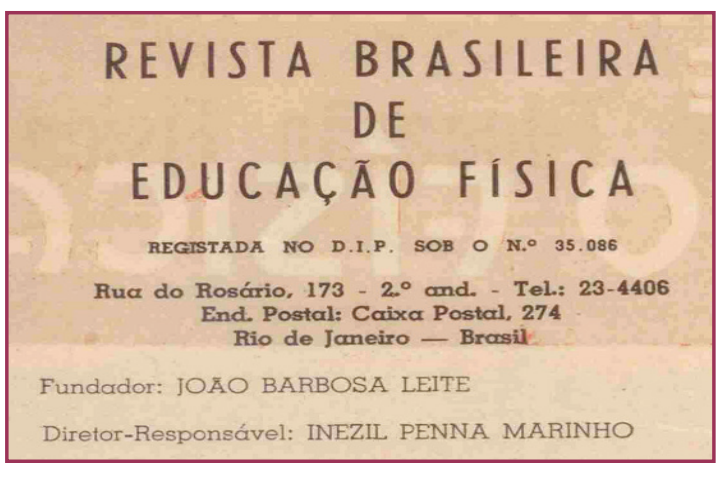


Essa nova empreitada na vida de Marinho aparece quando, segundo o autor, a Educação Física brasileira passava por "duros golpes" recebidos pela administração pública, precisando "[...] de todas as forças ainda disponíveis para colocá-las a serviço de sua redenção" (MARINHO, 1946b, p. 3). Sendo assim, a Revista Brasileira de Educação Física passa a ser a instituição em que Marinho ocupa seu lugar próprio (CERTEAU, 2004), mantendo o seu discurso político-pedagógico, visto que esse impresso lhe garantia voz dentro da área, pois, segundo Marinho (1946b, p. 3), a revista era um veículo de:

[...] renome e popularidade, quer nos Estados e Territórios do Brasil, quer em todos os países da America Latina e nos Estados Unidos que evidenciava o inestimável serviço que vinha sendo prestado a causa nacional da Educação Física, já na divulgação de noticiário e de conhecimentos básicos, já na discussão de problemas da maior relevância.

Essa prática de produção de uma memória de sua própria inserção no campo da Educação Física evidencia a importância de deixar registros para se constituir autoridade no campo científico (BOURDIEU, 1983).

Observamos a intenção de Marinho em se constituir como autoridade científica com voz autorizada e com legitimidade para falar em nome da Educação Física, sobretudo no que se refere à História. A mesma ação é feita para dar destaque à sua participação em concursos, para dar visibilidade às palestras e eventos que ele proferia, conforme fragmentos abaixo:

A convite do Diretório Central dos Estudantes, realiza as seguintes palestras pelo microfone da Rádio Ministério da Educação: Que meios utilizavam os nossos índios para a sua Educação Física?, Poderá ter a Educação Física alguma influência na formação do tipo racial que o brasileiro representará no futuro? 0 aspecto sociológico do problema da seleção da espécie no Brasil e Poderá a Civilização Moderna prescindir da Educação Física? De 5 a 28 de outubro a Divisão de Educação Física do Ministério da Educação e Saúde, em cooperação com as Divisões de Aperfeiçoamento e de Seleção do Departamento de Administração do Serviço Público, promove uma série de palestras, tendo por finalidade dar aos candidatos a Prova de Habilitação para Inspetor de Ensino Secundário os conhecimentos indispensáveis ao desempenho desta função, na parte que se refere à Educação Física. Dentre as doze palestras 07 foram ministradas pelo Prof. Inezil Penna Marinho [...] (MARINHO, 1954, p. 179-182).

Uma leitura das citações apresentadas evidencia a forma como Marinho usava os lugares que ocupava, como é o caso da Divisão de Educação Física do Ministério da Educação e Saúde, para participar, como convidado, de diferentes eventos no Brasil e no exterior, fortalecendo sua imagem como autoridade na área, mas, ao mesmo tempo, evidenciando 0 reconhecimento dos pares à sua produção.

Observamos também em Marinho (1954) a participação, no período de 19 a 31 de julho de 1943, no Primeiro Congresso Pan-Americano de Educação Física realizado no Rio de Janeiro, por iniciativa da Divisão de Educação Física do Ministério da Educação e Saúde. Marinho participa da organização da Secretaria-Geral Provisória. Vale lembrar que ele era servidor efetivo daquela divisão, na qual exercia o cargo de Técnico em Educação.

No entanto, sua participação não se deu exclusivamente nas atividades técnicoadministrativas. Foram apresentados também os seguintes trabalhos: "Do valor bio-psicosocial do jogo em particular e dos exercícios físicos em geral: a sua influência na formação do 
caráter e mesmo na sua modificação e $\mathrm{O}$ grupamento homogêneo e as considerações que 0 problema suscita" (MARINHO, 1954, p. 291).

Os textos em circulação nesse evento evidenciam a perspectiva defendida pelo autor de que a Educação Física representa um veículo de aproximação entre os povos do Novo Continente com o objetivo de formar uma só nação. Para isso, sinaliza a Educação Física como forma de produzir a homogeneização construindo um padrão corporal, mas, ao mesmo tempo, preservando a identidade cultural. Ainda assim, Marinho opta por não traçar um plano pan-americano de Educação Física.

É impossível, completamente inexeqüível para não dizer inadmissível, pretender impor a qualquer país a adoção de um plano de educação física, ainda que sob o rótulo de panamericano, caso o mesmo não consulte ou não corresponda aos interesses e às necessidades da nação. Seria atentar contra a sua soberania, contra a liberdade de escolher e fixar as normas educacionais capazes de assegurar a continuidade de seu patrimônio cultural. Assim, um plano de tal envergadura só poderá surgir quando todos os países da América estiverem perfeitamente identificados em seus ideais, quando os interesses de cada um refletir os dos demais, quando, enfim, a América inteira se comportar como se fosse uma só nação (MARINHO, 1948a, p. 32-33).

Percebemos que Marinho circulou suas ideias construindo sua identidade numa rede de instituições tanto de caráter físico quanto jurídico na Educação Física. Em 15 de outubro de 1943, juntamente com o Dr. Paulo Frederico de Figueiredo Araújo, funda a Sociedade de Estudos nos Problemas da Educação Física (Sepef), que se propunha dedicar-se aos estudos da Educação Física e divulgar trabalhos com eles relacionados. Nessa sociedade, seus estudos alcançam os primeiros lugares no "Concurso de Contribuições para o Método Nacional de Educação Física" e no "Concurso de Trabalhos sobre Educação Física", ambos promovidos pela Divisão de Educação Física do Ministério da Educação e Saúde (MARINHO, 1954).

Marinho aparece ainda como autoridade oficial da Educação Física brasileira, por exemplo, no período de 13 a 20 de dezembro de 1943, quando representou o Brasil no Primeiro Congresso Argentino de Educação Física, realizado em Buenos Aires, apresentando trabalho sobre as bases científicas da Educação Física - Fundamentos científicos da educação em geral e da educação física em particular (MARINHO, 1954).

O envolvimento de Marinho na Educação Física não se dá apenas por via das atividades de docência, pois, exercendo o cargo de Técnico de Educação, ele se dedica também à produção de trabalhos científicos. A exemplo, o Diário Oficial de 14 de junho de 1944 publica o resultado do "Concurso de Monografias de 1943", promovido pela Divisão de Aperfeiçoamento Administrativo do Serviço Público, no qual se classifica em terceiro lugar da seção Pessoal, com o trabalho $O$ aperfeiçoamento físico do servidor do Estado e a sua influência no rendimento do serviço público, em parceria com Paulo F. F. Araújo (MARINHO, 1954).

Ainda investido no cargo de Técnico em Educação, sua participação era solicitada em eventos correlatos à Educação Física, tendo em vista que, dentro da Divisão de Educação Física do Ministério da Educação e Saúde, era o único especializado na área. Assim, em junho de 1944, designado pelo ministro da Educação e Saúde, realiza pesquisas no Instituto Benjamin Constant, para discutir o problema da Educação Física das crianças cegas no Brasil. No período de 23 a 30 de agosto de 1944, a convite da Divisão de Aperfeiçoamento do Departamento Administrativo do Serviço Público, realiza a "Campanha de Aperfeiçoamento 
Físico do Servidor do Estado", apresentando um plano de trabalho que culminava com uma olimpíada entre os funcionários das diversas repartições públicas (MARINHO, 1954).

Conforme anunciado, Marinho proferiu conferências no Brasil e em países do exterior, como a Argentina, que constituía um roteiro bastante frequentado por ele, onde desempenhou o papel de agente divulgador das ideias da Educação Física brasileira. De acordo com seus registros,

O Prof. Inezil Penna Marinho realiza no auditório do Ministério de Educação e Saúde, a 31 de maio de 1944, no auditório do Instituto de Educação de Porto Alegre, a 5 de junho, no auditório da Escola de Professores de Curitiba, a 9 de junho, no salão n. 4 do Estádio do Pacaembu, em São Paulo, a 13 de junho, e no auditório da Escola de Professores de Vitória conferências sobre o tema ' $O$ Método Nacional de Educação Física'. Em Buenos Aires, de 11 a 16 de dezembro de 1944, realiza-se a Segunda Conferência de Professores de Educação Física, sob o patrocínio da Associación de Professores de Educação Física, tendo sido aprovados três trabalhos apresentados pelo Prof. Inezil Penna Marinho, com os títulos 'Objetivos e características da educação física no ensino secundário', 'Papel da educação física na preparação militar' e 'O problema do grupamento homogêneo no Brasil' (MARINHO, 1954, p. 393).

Ele mesmo anuncia que foi ainda designado, pela Portaria $n^{\circ} \mathbf{2 1 8}$, de 18 de maio de 1944, do Departamento Nacional de Educação, para orientar e fiscalizar a Escola de Educação Física do Estado do Rio Grande do Sul, o Curso Normal de Educação Física do Estado de Santa Catarina, a Escola de Educação Física e Desportos do Paraná, a Escola de Educação Física e Desportos do Estado de São Paulo e a Escola de Educação Física do Estado do Espírito Santo (MARINHO, 1954).

Considerando as atividades pedagógicas por ele realizadas, quando se dá a construção de sua produção acadêmica na qualidade de Técnico em Educação, acredita-se que suas intervenções não se restringiam aos espaços e lugares da Divisão de Educação Física, conquistando gradativamente autoridade na área. Além disso, era convidado cada vez mais a proferir suas palestras em instituições brasileiras, como ele mesmo afirma:

De 22 a 28 de junho, sob o patrocínio da Associação Brasileira de Educação, realiza-se no Rio de Janeiro o IX Congresso Nacional de Educação, dedicado ao sentido democrático que deverá nortear a educação. O Professor Inezil Penna Marinho apresenta tese 'O Sentido Democrático da Educação Física' (MARINHO, 1954, p. 440).

13 de setembro de 1945 o 'Diário Oficial' o seguinte resultado apresentado pela comissão julgadora do 'Concurso de Contribuições para o Método Nacional de Educação Física': 1 lugar - 'O Método Nacional de Educação Física - Sua origem', de Inezil Penna Marinho; 20 lugar - 'Estudo comparado entre o Método Nacional de Educação Física e o Método Francês', de Inezil Pena Marinho e $3^{\circ}$ lugar - 'O Método Nacional de Educação Física - Evolução', de Inezil Pena Marinho (MARINHO. 1954, p. 443-444).

A 28 de setembro de 1945 o 'Diário Oficial' publica o seguinte resultado apresentado pela comissão julgadora do 'Concurso de Trabalhos sobre Educação Física' - Seção Técnico-Pedagógica. 10 lugar - Inezil Penna Marinho - 'Análise do Sistema de Ginástica de Niels Bukh'; 2 lugar - Inezil Penna Marinho - 'Lugar da Educação Física no Plano Educacional'; e 3ํ lugar - Inezil Penna Marinho - 'Análise do Método da Escola de Joinville-le Pont'. A $1^{\circ}$ de novembro de 1945, o 'Diário Oficial' publica o seguinte resultado apresentado pela Comissão Julgadora do 'Concurso de Trabalhos sobre Educação Física'. Na seção Técnico-pedagógica o 
Professor Inezil Penna Marinho ganha $01^{\circ}$ lugar com 'Metodologia do Treinamento Desportivo da Luta Livre' e o 3 ㅇ lugar com 'Metodologia do Treinamento Desportivo do Volibol em duplas' (MARINHO, 1954. p. 444-445).

A 8 de novembro de 1945, o 'Diário Oficial' publica o resultado apresentado pela Comissão Julgadora do 'Concurso de Trabalhos sobre Educação Física' - seção Técnico-biológica: 1 @ lugar - Inezil Penna Marinho - 'Regime de Atividades Físicas para crianças Cegas'; 3ํlugar - Inezil Penna Marinho - 'Educação Física para desajustados da conduta' (MARINHO, 1954, p. 445-446).

Diante dessas informações e práticas, consideramos que a presença de Marinho em diferentes lugares e espaços de representação dentro do campo contribuiu para sua formação acadêmico-profissional, proporcionando visibilidade e circulação de seus escritos numa busca que objetivava se constituir autoridade na área da Educação Física.

No entanto, é preciso ressaltar que, para compreender a autoconstrução e a projeção desse ator social em seu tempo, é necessário considerar a estratégia por ele empregada, o que possibilitava a circulação de suas experiências profissionais pela via dos artigos, livros e revistas. Esse era o seu modo de garantir a evidência de suas ideias e propostas. A esse processo de construção de monumento Le Goff $(2003$, p. 526) denomina "[...] tudo aquilo que pode evocar o passado e perpetuar a recordação [...]". Esse foi o modo utilizado pelo autor para se destacar e se constituir como referência para a área.

No tocante aos estudos sobre História, deve ser feita referência às obras Contribuição para a história da educação física no Brasil (1943), História da educação física e dos desportos no Brasil (1952, 1953 e 1954) e História da educação física no Brasil (1984).

Para Melo (1998), a produção de Marinho, em relação à História da Educação Física, pela orientação, pela peculiaridade e pela intensidade, marca uma importante fase sobre essa temática no Brasil, embora suas opções metodológicas e operações teóricas sejam passíveis de diferentes críticas.

É grande a produção intelectual de Marinho, contudo é preciso problematizar sua intensidade e as formas usadas. É interessante notar que 0 autor publica em diferentes dispositivos de circulação, como livros, manuais, apostilas, revistas. Além disso, estabelece, como ação tática (CERTEAU, 2004) para fazer circular sua produção, a publicação de pesquisas em diferentes estágios de desenvolvimento, utilizando a seguinte estratégia: publica um artigo em periódico, posteriormente amplia as reflexões desse estudo, divulgando-o em outras fontes, como congresso, apostilas e livros.

Essa estratégia pode ser observada, a título de exemplo, em seu texto Grupamento homogêneo: considerações em torno desse problema em educação física, veiculado na Revista Educação Physica, n. 65, de 1942, e, posteriormente, nos Anais do Congresso Pan-Americano de Educação Física, novamente na Revista Brasileira de Educação Física, n. 7, de 1944, e na Revista Brasileira de Educação Física, ano 2, de 1945.

Observamos ainda uma repetição de publicação de trabalhos em diferentes fontes. Essa ação contribui para 0 aumento quantitativo da produção do autor, dificultando a análise da intensidade dessa publicação. Assim, mudam-se as formas de divulgação, mas os trabalhos continuam os mesmos. Vemos, nesse caso, a publicação repetida de monografias, ensaios, conferências, teses para concursos, artigos, em fontes como: Revista Educação Física; Revista Brasileira de Educação Física; Cultura Política; Arquivos da Escola Nacional de Educação Física 
e Desportos; Jornal dos Sports; Revista Brasileira de Estudos Pedagógicos; Revista do Serviço Público; O Jornal Boletim da Diretoria de Esportes de Minas Gerais; Revistas Estrangeiras (Revista de Medicina Aplicada a los Desportes; Educación Física y Trabajo, Nueva Era; Revista Ecuatoriana de Educación Física, El Salvador Desportiva). Exemplo dessa prática pode ser observado nos trabalhos $O$ eterno problema do grupamento homogêneo, Os clássicos e a educação física e Subsídios para a história da capoeiragem no Brasil.

Essa prática de circulação também foi evidenciada por Goellner (2005, p. 14), que, durante uma pesquisa ao acervo pessoal de Inezil Penna Marinho, se deparou com uma monografia desse autor, intitulada Lugar da educação física no plano educacional, escrita em 1945, que "[...] foi desdobrada em vários textos, capítulos de livros e comunicações ou conferências apresentadas em congressos nacionais e internacionais".

Marinho usou ainda, estrategicamente, o lugar que ele ocupava, sobretudo na direção da Revista Brasileira de Educação Física, para divulgar suas funções ligadas à advocacia. Encontramos exemplos em diversos volumes e na mesma área dos estudos por ele publicados.

À guisa de exemplificação, apresentamos a Figura 4, em que se registra a propaganda dos serviços de advocacia prestados por Marinho, que aparece na Revista Brasileira de Educação Física (ano III, n. 28, 1946), junto ao artigo intitulado Os cegos e a educação física, assinado pelo professor Armando M. Monti (do Instituto Roman Rossell, de Buenos Aires), com tradução de Marinho.

Figura 4 - Anúncio do escritório de advocacia de Inezil Penna Marinho

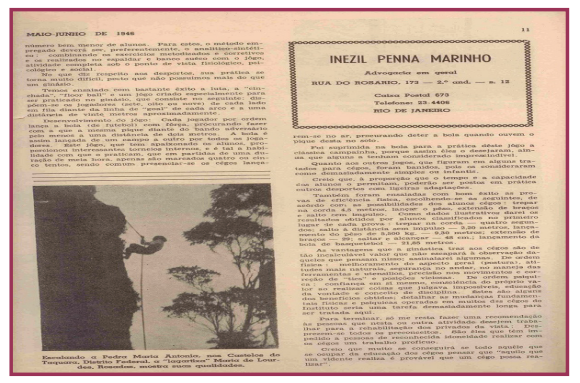

Fonte: Revista Brasileira de Educação Física, v.3, n. 28, p. 11, 1946.

Essa prática empregada por Marinho, por meio dos usos do impresso periódico de caráter comercial, deu-se pelo fato de essa revista necessitar de seus anunciantes para cumprir suas responsabilidades financeiras, configurando-se, a exemplo de outro periódico, como: "[...] um estande, local em que se expõem variados produtos e serviços ao público leitor" (SCHNEIDER, 2010, p. 129).

Observamos ainda, conforme Figura 5, que o escritório de advocacia de Marinho funcionava na mesma área física da direção da Revista Brasileira de Educação Física.

Figura 5 - Endereço da Revista Brasileira de Educação Física

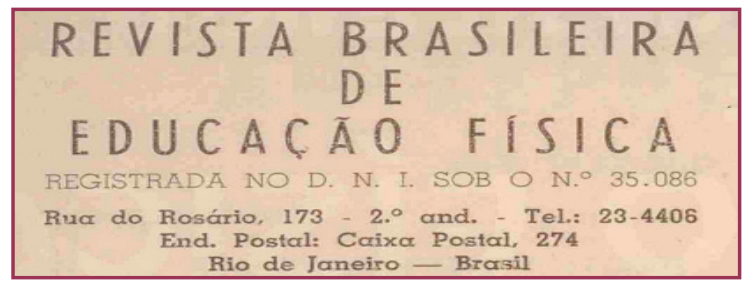

Fonte: Revista Brasileira de Educação Física, v. 3, 28, p. 2, 1946. 
Segundo Marinho (1950), esse fato ocorreu durante o início de sua direção, em 1946, quando padecia de todos os tipos de dificuldades: "Estávamos na terça parte de uma sala à Rua do Rosário, 173 - 2 andar, por gentileza de outro amigo, Henrique Rodrigues". No mesmo artigo, Marinho (1950, p. 3) destaca ter "[...] conseguido aumentar o número de assinantes e dobrar a tiragem [...] de exemplares. Porém quanto à publicidade, pilar de sustentação de qualquer órgão, [reclama] continuava paupérrima".

Outra estratégia utilizada por ele para se constituir autoridade científica no campo da Educação Física é o uso do periódico como meio de divulgação e comercialização de seus livros, manuais e apostilas (Figura 6).

Figura 6 - Divulgação de trabalhos publicados por Inezil Penna Marinho

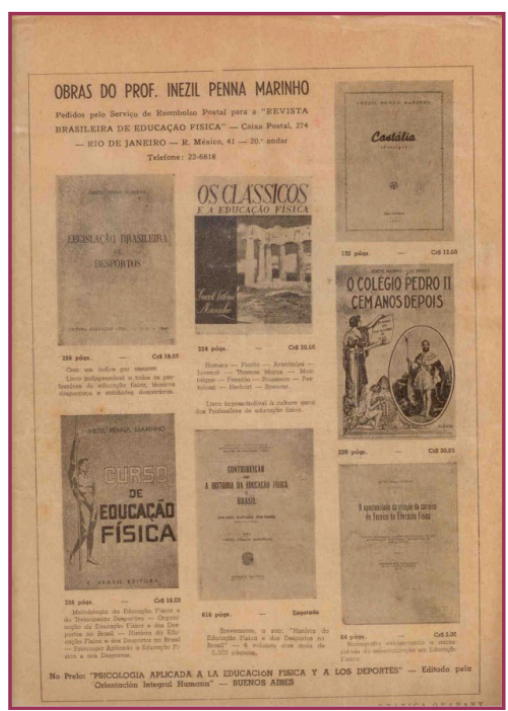

Fonte: Revista Brasileira de Educação Física, v.4, n. 38, p. 44, 1947.

A unificação desses lugares (escritório de advocacia e direção do periódico) se constituía como contexto capaz de fortificar o discurso da prática política e acadêmica de Marinho e também como espaço de aproximação da representatividade desse ator no campo do Direito e da Educação Física.

\section{INEZIL PENNA MARINHO: A PRODUÇÃO EM PERIÓDICOS DA EDUCAÇÃO FíSICA}

Foram mapeados 178 trabalhos no período de 1940-1958 nos seguintes periódicos: Revista de Educação Física, Educação Physica, Revista Brasileira de Educação Física e Arquivos da Escola Nacional de Educação Física e Desportos. Com base na leitura dos artigos, construímos categorias de análise que permitiram o seu agrupamento em razão dos conteúdos específicos abordados:

Educação Física (79 artigos): o perfil temático gira em torno de epistemologia, política educacional, investimento financeiro, valorização profissional, formação profissional, prescrição de exercícios físicos, metodologia de ensino da Educação Física;

História da Educação Física brasileira (69 artigos): dentre esses temas, destacamos seminários e palestras, registro de personalidades e legislação sobre a Educação Física brasileira;

Teorias Educacionais (11 artigos): enfatizam as propostas de modelos educacionais, visando à criação de um método brasileiro de Educação Física, além de estudos ligados à Psicologia, à Filosofia e à Sociologia.

Outras (19 artigos): assumem naturezas diversas, como poemas e traduções. 
No Gráfico 1, apresentamos uma relação com 0 ano e número de publicações de Marinho realizadas em todos os periódicos de nosso estudo. 0 ano com maior recorrência de publicações foi 1944, com 35 trabalhos (19,7\%), seguido de 1947, com 30 trabalhos (16,0\%).

Gráfico 1 - Distribuição de frequência de acordo com o ano

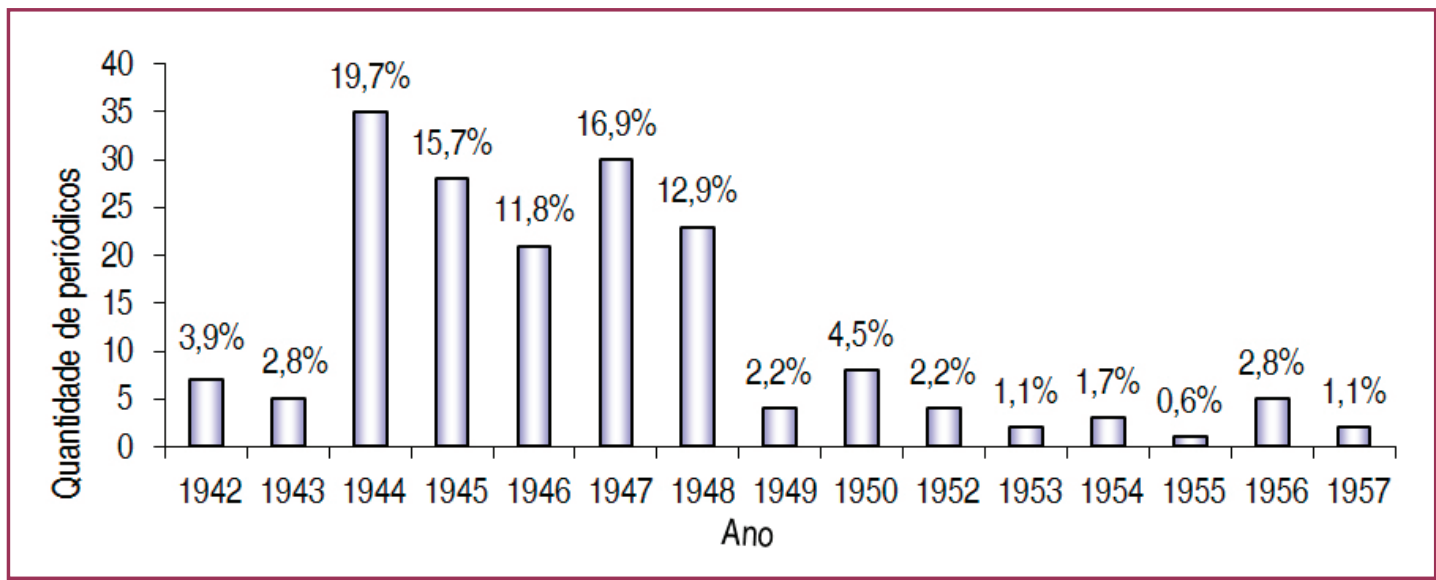

Fonte: Dos autores.

A análise do volume de publicações e o longo período de permanência e circulação de Marinho nos dão indícios de que ele tinha trânsito autorizado nos periódicos, principalmente na Revista Brasileira de Educação Física, da qual esteve à frente no período de 1946 a 1952 , na condição de proprietário e diretor-geral. Tal inserção no campo editorial evidencia o forte capital simbólico adquirido e produzido ao longo dos primeiros anos de sua carreira na área de Educação Física, fruto, inclusive, da sua função como Técnico em Educação Básica na Divisão de Educação Física do Ministério da Educação e Saúde. Como visto, a ocupação desse cargo Ihe oportunizou representar aquela divisão na área da Educação Física, divulgando seu pensamento em defesa da causa da Educação Física no Brasil e no exterior.

Somados os percentuais de publicações realizadas no período que compreende os anos de 1944 a 1948, teremos 77\% do total pesquisado. Nota-se que, nos impressos estudados, Marinho inicia suas publicações em 1942, com 3,9\%, e em 1943, com 2,8\%, tendo um período de grande produtividade, constância e estabilidade de 1944 a 1948, vindo a decrescer em volume de produção a partir do ano de 1949.

Esses resultados nos instigaram a pesquisar os recursos estratégicos de produção editorial utilizados para se manter por tanto tempo em circulação. Percebemos, desse modo, indícios de que o número de páginas correspondentes às publicações funcionou como dispositivo editorial nos termos de Chartier (1988). Em contrapartida, essa estratégia constitui-se em um recurso utilizado que contribuiu para a regularidade que manteve Marinho em circulação.

É preciso destacar ainda a natureza das produções, já que ele usava, principalmente, a Revista Brasileira de Educação Física para divulgar relatórios e noticiários referentes a congressos, conferências e reuniões realizados no Brasil e no exterior.

Outra estratégia usada era a divisão dos textos, apresentando-os por partes publicadas ao longo de várias edições, além de veicular o mesmo artigo em periódicos diferentes, como visto no tópico anterior. 
A publicação sobre assuntos diversos, não somente Educação Física, mas associados à Filosofia, Psicologia, Sociologia, poesia e traduções, contribuiu para o aumento quantitativo da produção de Marinho.

A partir da década de 1950, sua produção em periódicos se torna menos frequente, muitas vezes com a publicação de textos revisados. Tal manobra não impediu sua participação nas discussões inerentes à Educação Física, visto que seu foco também se direcionou para outros temas.

O Gráfico 2 representa a frequência de produção de trabalhos em relação aos periódicos.

Gráfico 2 - Distribuição de frequência de acordo com o periódico

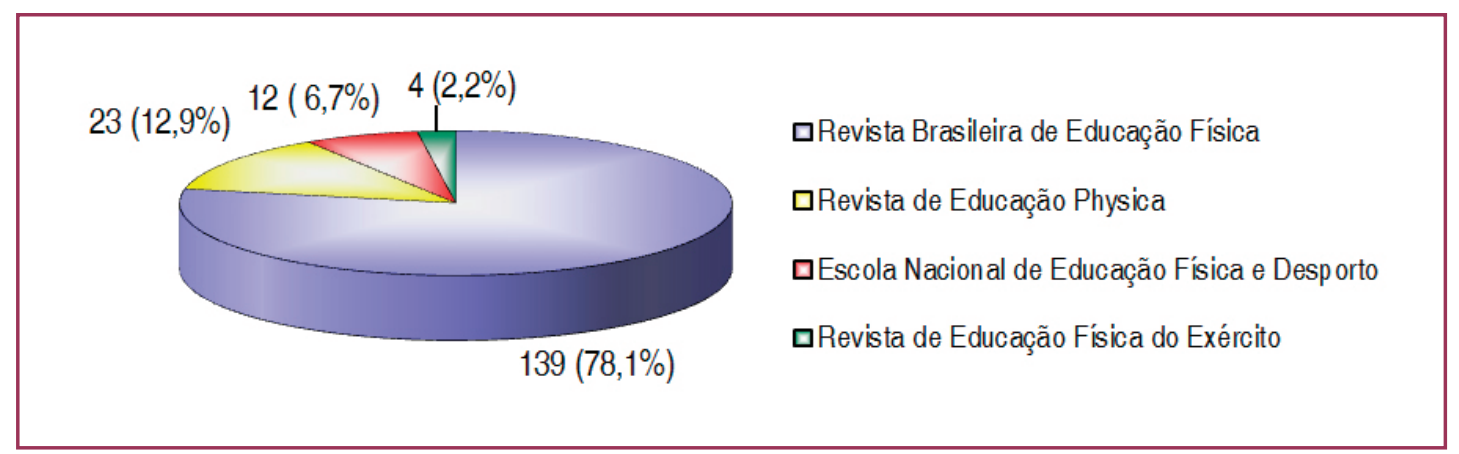

Fonte: Dos autores

Marinho foi proprietário e diretor-geral da Revista Brasileira de Educação Física, cabendoIhe decidir o que seria posto em circulação no periódico. Outro fato a considerar é que a revista Educação Physica circulou no período de 1932 a 1945, e as publicações de Marinho começaram a constar nos periódicos especializados a partir da década de 1940. Verificamos que, em 1942, foram veiculadas dez revistas, seis das quais continham artigos de Marinho; em 1943, há registro de cinco; em 1944, ele publica nove matérias; finalmente, em 1945, são três publicações.

Diante desses registros, temos, em quatro anos, a produção de 23 publicações, numa média de seis por revista. Esse dado revela, proporcionalmente, um alto ritmo de produção intelectual.

A participação de Marinho na Revista de Educação Física do Exército foi tímida, tendo em vista que, em 1942, publica uma matéria registrando decretos, portarias e leis referentes à Educação Física e, somente na década de 1950, volta a participar com mais três publicações.

Na revista Arquivos da Escola Nacional de Educação Física e Desportos, temos uma concentração da produção na década de 1950. Esse periódico era responsável por difundir as pesquisas realizadas na Escola Nacional de Educação Física e Desportos. A inserção de Marinho como catedrático dessa escola ocorre justamente nesse período, o que pode ter influenciado esse resultado.

O Gráfico 3 mostra o ritmo de produção por ano e periódico. Na revista Educação Physica, entre 1942 e 1945, foram publicados 23 (12,9\%) trabalhos. Nos Arquivos da Escola Nacional de Educação Física e Desportos, encontramos 12 (6,7\%) publicações no período de 1953 a 1957. Já a Revista Brasileira de Educação Física registrou 139 (78,1\%) trabalhos, entre 1944 e 1952. Na Revista de Educação Física do Exército, ele publicou um texto, no ano de 1942, e voltou a apresentar trabalhos nos anos de 1952, 1953 e 1954, totalizando quatro produções $(2,2 \%)$, com uma publicação por ano. 
Gráfico 3 - Distribuição de frequência de acordo com o ano e periódico

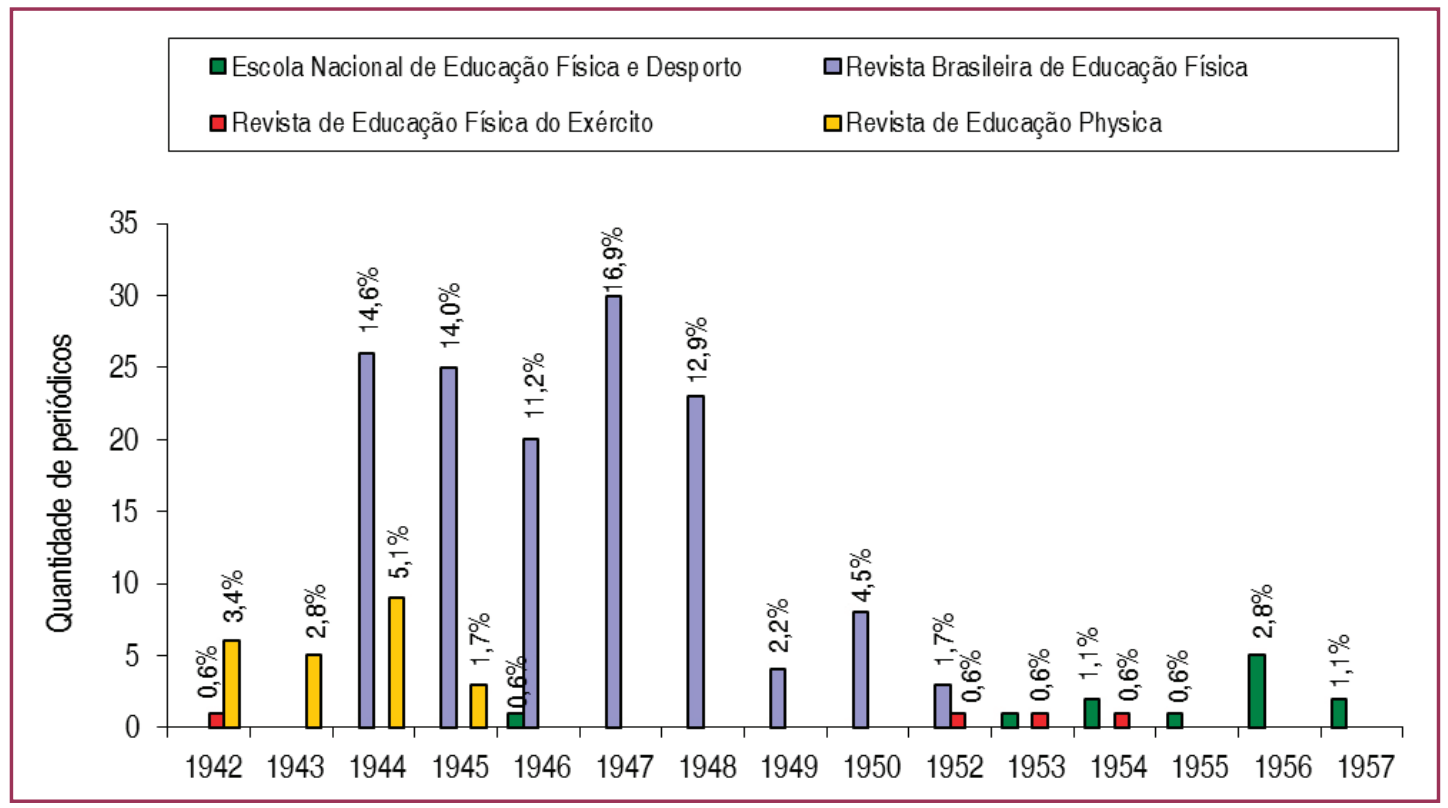

Fonte: Dos autores

Para efeito comparativo, apresentamos o período em que esses impressos circularam. A Revista Educação Física do Exército circula desde 1932 até os dias atuais; a revista Educação Physica, de 1935 a 1945; a Revista Brasileira de Educação Física, de 1944 a 1952; e, por fim, os Arquivos da Escola Nacional de Educação Física e Desportos, no período de 1945 a 1966.

O ano de 1947 representa o auge do ritmo de produção de Marinho na Revista Brasileira de Educação Física, onde assumiu a direção-geral em 1946. Nessa condição, orgulhava-se de conceituá-la como "[...] uma revista de ensino, de caráter privado e comercial. A revista que não apresentava cor política, nem se filiava a qualquer partido. Independente na defesa de suas idéias" (MARINHO, 1947, p. 5). Acreditamos que o fato de esse periódico não estar filiado a nenhum partido ou a nenhuma entidade política tenha possibilitado a Marinho um controle sobre a revista, facilitando, assim, a circulação de seus trabalhos, haja vista sua participação nesse impresso como diretor.

Precisamos levar em consideração o próprio quantitativo de periódico disponível no período de 1942 a 1945. Essa análise nos ajuda a compreender as investidas de Marinho na revista Educação Physica. Ou seja, ele procurava fazer circular seus artigos nos espaços existentes e a revista Educação Physica representava lugar de divulgação e diálogo com os pares da Educação Física, assim como a Revista Educação Física e os Arquivos da Escola Nacional de Educação Física e Desportos.

Ao utilizar esses espaços, a intenção de Marinho era produzir registros dele mesmo, por meio de documentos e testemunhos de sua formação, para que estudiosos da Educação Física pudessem ter como pesquisar sua obra, dada a sua capacidade de pensar uma ação intencionalizada, oferecendo subsídios suficientes para compreender sua atuação na Educação Física. Nesse movimento, a intenção é que outros transformem seus testemunhos em monumento, perpetuando, assim, toda a sua produção, inserção acadêmica, política e intelectual para as próximas gerações da Educação Física.

No Gráfico 4, apresentamos a distribuição de publicação por revista e categoria de análise. 
Gráfico 4 - Distribuição de frequência de acordo com o periódico e categoria

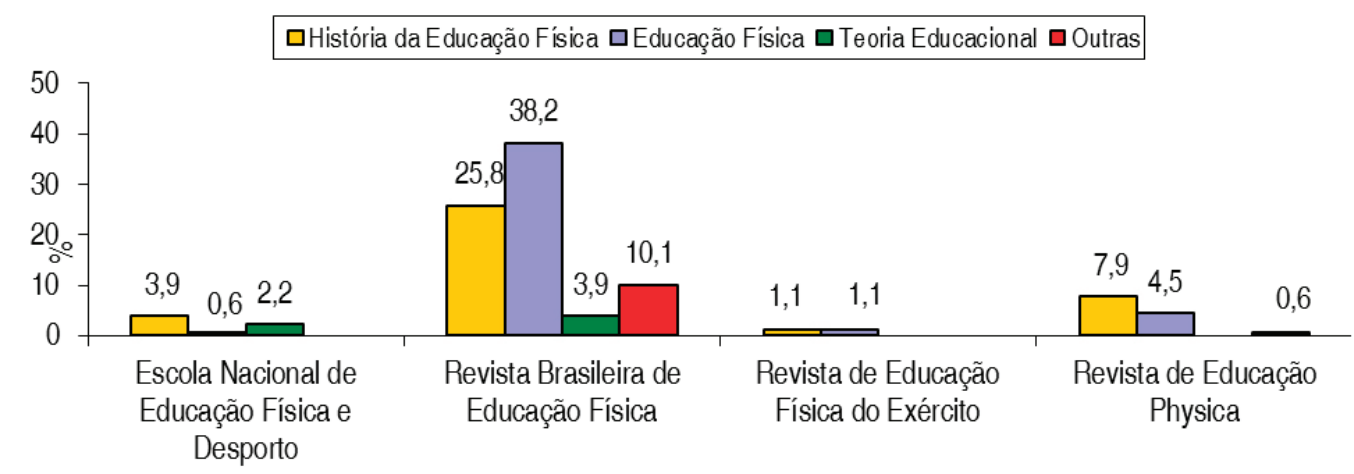

Fonte: Dos autores.

Já no início da carreira, Marinho se mostra inclinado aos estudos da Educação Física, sobretudo aos temas ligados à História. Atinge seu ápice quando, em 1956, assume a cátedra de História e Organização da Educação Física e dos Desportos na Escola Nacional.

No Gráfico 4, verificamos que, apesar de sua produção ter característica multidisciplinar, o maior percentual dos trabalhos se agrupa na categoria Educação Física.

Ao aproximar a Educação Física de outras áreas de conhecimento, relacionando-a com as Ciências Biológicas e as Sociais, Marinho se fez circular em variadas matérias. Esse dispositivo (CHARTIER, 1988) por ele utilizado para representar a Educação Física demonstra a sua busca em articular saberes oriundos de diferentes campos do conhecimento, como pode ser visto nos seguintes trabalhos: Os clássicos e a educação física, Fundamentos bio-sóciopsico-filosóficos dos programas de educação física na escola secundária, Psicologia aplicada à torcida e Discusión de los fundamentos sociológicos de la Educación Física, nos quais se entrecruzam Educação Física, História, Biologia, Psicologia, Filosofia, Sociologia.

O Gráfico 5 destaca a frequência das publicações em relação às categorias postas em estudo.

Gráfico 5 - Distribuição de frequência de acordo com a categoria

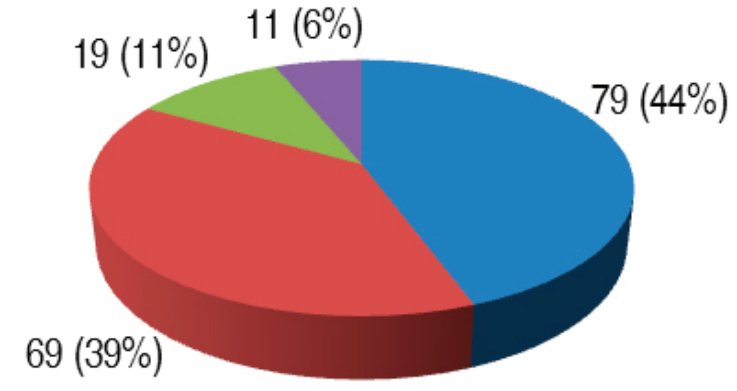

$$
\begin{aligned}
& \text { - Educação Física } \\
& \text { - História da Educação Física } \\
& \text { — Outras } \\
& \text { - Teoria Educacional }
\end{aligned}
$$

Fonte: Dos autores

Consideramos que, ao apropriar-se dos conceitos oriundos da Filosofia, Psicologia, Sociologia e História, Marinho tenha atentado para a necessidade de inter-relacionar a Educação Física com as Ciências Humanas e Sociais, abandonando o caráter exclusivamente 
biologista. Exemplo dessa perspectiva pode ser visto nos textos 0 conceito bio-sócio-psicofilosófico da educação física em oposição ao conceito anátomo-fisiológico e Fundamentos biosócio-psico-filosóficos dos programas de educação física na escola secundária. Para ele:

\footnotetext{
O homem deverá aspirar um mundo melhor e, para isso, desenvolver outras qualidades e capacidades que the permitam trabalhar para esse fim que the possibilitem a concretização desse ideal. 0 conceito bio-psico-sócio-filosófico traduz perfeitamente todas as necessidades que acabamos de apontar e resiste às mais severas críticas. Dentro de tal conceito, a Educação Física [...] é um processo individual e social, capaz não apenas de melhorar as condições físicas e psíquicas do indivíduo e integrá-lo na sociedade, perfeitamente ajustado, como ainda de desenvolver-lhe a personalidade, as qualidades potenciais para líder e permitir-lhe a perfeita compreensão e discussão dos problemas existentes (MARINHO, 1948b, p. 37).
}

A categoria Educação Física abrangeu uma diversidade temática que Marinho tanto soube vincular ao seu pensamento político-pedagógico como usá-la como meio de promover um discurso em defesa da área. Marinho não só apresentou seu posicionamento a respeito dos pressupostos que defendia, mas também criticou os que eram contrários aos seus propósitos para a consolidação e desenvolvimento da Educação Física, conforme se pode observar no texto O eterno problema do grupamento homogêneo (MARINHO, 1944a).

Esse resultado vem confirmar o pensamento pedagógico de Marinho, que não compreendia a Educação Física sem que esta estivesse fundamentada em bases filosóficas (MARINHO, 1972).

Em todos os anos, as publicações se concentraram nas categorias História da Educação Física e Educação Física. Os anos com maior quantidade de publicações foram 1944 (15) e 1945 (13), respectivamente. Na categoria Educação Física, os anos com maior quantidade de publicações foram 1944 e 1946; já em Teoria Educacional, foram, respectivamente, 1944 e 1948.

Ao realizarmos o mapeamento da produção de Marinho publicada nas revistas especializadas, observamos que as temáticas História da Educação Física, Educação Física, Teoria Educacional e outras nos possibilitaram compreender que esse autor buscava, entre as ciências, o entendimento para uma Educação Física que proporcionasse a regeneração, nacionalização e formação do povo brasileiro.

Desse modo, os lugares ocupados e os espaços praticados (CERTEAU, 2004) por ele constituíram representações na comunidade da área, dentro e fora do Brasil, uma vez que esse estudioso se construiu autoridade na Educação Física e tornou-se reconhecido como tal pelos seus pares.

\section{REFERÊNCIAS}

BOURDIEU, Pierre. Sociologia. Rio de Janeiro: Ática, 1983.

CERTEAU, Michel de. A invenção do cotidiano: artes de fazer. 10. ed. Petrópolis, RJ: Vozes, 2004.

CERTEAU, Michel de. A escrita da história. 2. ed. Rio de Janeiro: Forense Universitária, 2006. 
CHARTIER, Roger. A história cultural: entre práticas e representações. 2. ed. Rio de Janeiro: Difel, 1988.

FERREIRA NETO, Amarílio. A pedagogia no exército e na escola: a educação física brasileira (1880-1950). Aracruz/ES: Facha, 1999.

FERREIRA NETO, Amarílio et al. Catálogo de periódicos de educação física e esportes (1930-2000). Vitória: Proteoria, 2002.

GOELLNER, Silvana Vilodre (Org.). Inezil Penna Marinho: coletânea de textos. Porto Alegre: Universidade Federal do Rio Grande do Sul, Colégio Brasileiro de Ciências do Esporte, 2005.

GOELLNER, Silvana Vilodre. Nos recônditos da memória: acervo pessoal de Inezil Penna Marinho. Porto Alegre: Gênese, 2009.

LE GOFF, Jacques. História e memória. 5. ed. Campinas, SP: Editora da Unicamp, 2003.

MARINHO, Inezil Penna. Considerações sobre um plano panamericano de educação física.

Revista Brasileira de Educação Física, Rio de Janeiro, v. 5, n. 47, p. 32-33, fev. 1948 a.

MARINHO, Inezil Penna. Contribuição para a história da educação física no Brasil: Brasil

Colônia - Brasil Império - Brasil República. Rio de Janeiro: Imprensa Nacional, 1943.

MARINHO, I. P. A educação na evolução constitucional do Brasil. Revista Brasileira de Educação Física, Rio de Janeiro, v. 3, n. 27, abr. 1946a.

MARINHO, Inezil Penna. Um ano de nova direção. Revista Brasileira de Educação Física, Rio de Janeiro, v. 4, n. 38, maio 1947.

MARINHO, Inezil Penna. O eterno problema do grupamento homogêneo. Revista Brasileira de Educação Física, Rio de Janeiro, v. 1, n. 8, p. 5-17, ago. 1944a.

MARINHO, Inezil Penna. História da educação física no Brasil. Rio de Janeiro: Ministério da Educação e Saúde, Divisão de Educação Física, 1952a. v. 1.

MARINHO, Inezil Penna. História da educação física no Brasil. Rio de Janeiro. Ministério da Educação e Saúde, Divisão de Educação Física, 1952b. v. 2.

MARINHO, Inezil Penna. História da educação física no Brasil. Rio de Janeiro. Ministério da Educação e Saúde, Divisão de Educação Física, 1953. v. 3.

MARINHO, Inezil Penna. História da educação física no Brasil. Rio de Janeiro. Ministério da Educação e Saúde, Divisão de Educação Física, 1954. v. 4.

MARINHO, Inezil Penna. A história da minha direção. Revista Brasileira de Educação Física, Rio de Janeiro, v. 7, n. 73, p. 3, abr. 1950.

MARINHO, Inezil Penna. Metodologia filosófica e científica aplicada à educação física e aos desportos. Brasília: Horizonte, 1972.

MARINHO, Inezil Penna. O moderno conceito bio-psico-socio-filosófico da educação física.

Revista Brasileira de Educação Física, Rio de Janeiro, v. 5, n. 46, p. 36-38, jan. 1948b.

MARINHO, Inezil Penna. Nova direção. Revista Brasileira de Educação Física, Rio de Janeiro, v. 3, n. 28, maio/jun. 1946b. 
MARINHO, Inezil Penna. A organização da educação física no Brasil (conferência realizada no curso de informações, promovido pela Divisão de Educação Física em 1941). Revista Brasileira de Educação Física, Rio de Janeiro, v. 1, n. 7, p. 22-29, jul. 1944b.

MELO, Victor Andrade de. Inezil Penna Marinho: notas bibliográficas. In: FERREIRA NETO, A. (Org.). Pesquisa histórica na educação física. Aracruz: Faculdade de Ciências Humanas de Aracruz, 1998. v. 3, p. 48-68.

NASCIMENTO, Célia Carvalho do. Inezil Penna Marinho: o tempo de uma história. In: FERREIRA NETO, A. (Org.). Pesquisa histórica na educação física. Vitória: Ufes, Centro de Educação Física e Desportos, 1997. v. 2, p. 121-156.

SCHNEIDER, Omar. Educação Physica: a arqueologia de um impresso. Vitória: Edufes, 2010. 